\title{
LAS HISTORIAS DE LA LITERATURA Y LA ENSEÑ̃NZA PÚBLICA
}

\author{
GABRIEL NÚÑEZ RUIZ \\ Universidad de Almería
}

\begin{abstract}
El estudio de la relación existente entre las Historias de la literatura y el sistema educativo moderno tendría que dar respuesta, al menos, a preguntas como las que a continuación nos formulamos: ¿Qué contenidos eligen las Historias de la literatura para la educación de los jóvenes? ¿Cómo se seleccionan estos, con respecto a las retóricas, nuevos contenidos? ¿En qué situación queda la Retórica clásica a partir de 1845? ¿Qué ideas estéticas, lingüísticas, ideológicas o políticas cimentan, transfieren a las aulas y divulgan las Historias de la literatura desde 1845 ?

En primer lugar, describiremos el modelo de educación literaria que hemos denominado retórico y el modo en que se produce el desplazamiento de la Retórica de las aulas escolares hasta ser gradualmente sustituida por la Historia de la Literatura.

Hasta 1845, la formación de los escolares de secundaria de las cátedras de Latinidad de aquella España está basada fundamentalmente en el aprendizaje de las reglas de las retóricas y en la imitación de los modelos clásicos. Desde comienzos del siglo XIX, colectivos como los afrancesados y las elites liberales, todavía tan influidos por el pensamiento ilustrado, esgrimieron insistentemente que el saber es ante todo «saber hablar bien», es decir, conocer las bellas letras en tanto que «arte de hablar y de escribir». La finalidad del estudio de las humanidades, por tanto, no era otra que la de expresar correctamente nuestros pensamientos. Así, la literatura, la elocuencia y la gramática, al participar del principio común que podríamos denominar como «el arte del lenguaje», tenían que contribuir a restablecer la racionalidad del uso idiomático. Y esto debía hacerse siguiendo una guía retórica que permitiera convertir tal principio en realizaciones sociales mediante programas culturales ligados a la política y a la educación pública. Precisamente, aquí radica la importancia de las bellas letras o, como le gustaba decir a Larra, la importancia del estudio filosófico de las humanidades. El fin, según Jovellanos, de las disciplinas humanísticas
\end{abstract}

Rlit, LXVI, 131 (2004), 77-85 
no era otro que «la exacta enunciación de nuestros pensamientos por medio de palabras claras, colocadas en el orden y serie más convenientes al objeto y fin de nuestros discursos» ${ }^{1}$. Quizá por la influencia de Condillac y de Hugo Blair nuestras retóricas insisten en las normas que deben guiar el proceso de aprendizaje del estilo, el cultivo de la imaginación como facultad nuclear de nuestra actividad teórica y la educación del gusto en tanto que exactitud del juicio. Y todo ello ha de lograrse mediante la educación linguística y estética. La importancia que Condillac concede a la Gramática estriba en el papel que otorga a la corrección formal, a la puritas, como condición indispensable para el uso de un lenguaje sin vicios y, por tanto, para la adquisición del estilo. Y la belleza de estilo depende de la claridad, de la comprensibilidad del discurso, es decir, de la correspondencia entre ideas y palabras y del orden de construcción del mismo, por un lado; y por otro, del carácter del estilo, o sea, de su emotividad y del asunto tratado. Los autores españoles que, como Matute, proponen la supremacía del aprendizaje de la poesía sobre los demás aprendizajes lo justifican argumentando lo siguiente: ésta nos ayuda a desarrollar las facultades necesarias mediante las que exponer nuestras ideas y, además, la reflexión y análisis de los poemas nos hacen ejercitar nuestros pensamientos y nuestra imaginación. «No siempre la juventud - explica Matute- necesitará dedicarse al profundo estudio del cálculo...; más jamás podrá dispensarse de cultivar sus talentos hasta el punto de poder explicar sus ideas» ${ }^{2}$. Hasta este extremo llegó en España el interés por la educación lingüística y por la modalidad artística que la literatura encarna ${ }^{3}$. Y Blair, cuyo Compendio sobre la Retórica y bellas letras fue reimpreso seis veces en España y Latinoamérica, dedica la lección segunda de sus Lecciones al gusto como facultad perfectible mediante un plan de ejercicios trazados para tal fin en el marco del sistema educativo. Una vez formado el mismo, el estudiante estará en condiciones de sentir placer o desagrado con las bellezas o defectos de las obras artísticas.

Este modelo de educación literaria basado en la Retórica estuvo vigente hasta la implantación de las Historias de la literatura, necesarias a las burguesías de España y de la América Hispana para asentar su concepto de nacionalidad y su independencia de la Metrópoli.

A modo de síntesis, podríamos decir, pues, que el modelo que denominamos retórico consistió básicamente, y hasta mediados del XIX aproxima-

\footnotetext{
${ }^{1}$ M. G. DE Jovellanos, Obras en prosa, Madrid, Castalia, 1978, p. 210.

2 J. MATUTE, «Reflexiones a favor de las Humanidades, extractadas de un discurso sobre el estudio de las matemáticas, de la química y de las letras humanas, que leyó en la Real Sociedad Patriótica de Sevilla en 24 de Marzo de 1803 Don...su individuo», en Correo Literario y Económico de Sevilla, tomo II (núm. 45) pp. 73-76, p. 74.

${ }^{3}$ M. GARRIDO PALAZÓN, La filosofía de las Bellas Letras y la historia literaria en España, Almería, IEA, 1992.
} 
damente, en el aprendizaje de las reglas del buen decir y de los principios que habrían de guiar a los escolares en el momento de componer obras literarias; y a la vez, en la consagración y canonización de los clásicos grecolatinos como ejemplos a los que imitar a la hora de escribir o hablar bien. Así formula la necesidad de las reglas el propio Gil de Zárate: «El arte, pues, de hablar y escribir con perfección, es un arte que deben los hombres poseer como indispensable, no sólo para los altos fines de la sociedad, sino también para los usos más comunes de la vida. Pero este arte, ¿lo puede adquirir el individuo por sí sólo, en virtud de sus propios recursos, sin más esfuerzos que los de su ingenio; o necesita preceptos, reglas que le señalen el sendero que ha de seguir para no perderse? ¿Deberá el hombre entregarse a sus propias inspiraciones, o convendrá cortar el vuelo a estas para corregir sus extravíos y darles la dirección oportuna? En suma, el arte de hablar y escribir, ¿necesita o no reglas? Esta es la primera cuestión que se nos ofrece, cuestión más'interesante ahora que nunca, pues hemos llegado a tiempos en que se ha dado en despreciar las reglas como rémoras de la imaginación que coartan y deslucen sus más nobles destellos. ¿Qué hay en el arte de escribir que le diferencie de las demás artes, para eximirle de la pensión común a todas? ¿Por qué se necesitarán reglas y estudios para ser un buen pintor, y no se habrán menester para ser orador o poeta?» ${ }^{4}$. Y es que desde el influyente manual de Hugo Blair se generalizó en el sistema educativo la idea de que, aunque las reglas no pueden crear el ingenio, sí pueden ayudarlo y corregirlo señalando los modelos dignos de imitación: aquellos que poseen las bellezas principales que los escolares deben conocer y estudiar.

Sin embargo, en las prácticas escolares concretas este modelo retórico - como demostramos recopilando los exámenes de escolares del XIX y mostrándolos en nuestro libro Educación y literatura ${ }^{5}$-, quedó reducido al aprendizaje de una copiosa ristra de figuras, reglas y preceptos que los escolares memorizaban, cuando no a la escritura y recitación, con el pretexto de la adquisición de dichas reglas, de otros preceptos relativos a la moral, que acabaron desplazando el aprendizaje de las convenciones literarias y sustituyéndolo por la enseñanza de máximas generalmente relacionadas con la religión y la moral. Valga este ejercicio de un escolar de Almería para comprender la derivación de la retórica hacia el control de los comportamientos de los escolares: "Tengo necesidad de preguntar muchas cosas a los jóvenes que estudian el segundo año. Primeramente, si han cumplido todas sus obligaciones y se han dedicado con asiduidad al estudio; en se-

${ }^{4}$ A. GIL DE ZÁRATE, Manual de Literatura. Principios generales de retórica y poética, Primera parte, Madrid, Imprenta de Martínez Minuesa, 1850, 5. ${ }^{a}$ ed., pp. 6-7.

${ }^{5}$ G. NÚÑ̃Z RUIZ, Educación y literatura. Nacimiento y crisis del moderno sistema escolar, Almería, Zéjel, 1994. 
gundo lugar, si han notado cuanta diferencia hay de un niño aplicado a las letras y a la enseñanza al que descuida los estudios, adornos y consuelos de la vida. Por último, si han procurado imprimir en su alma los saludables consejos de sus catedráticos y los preceptos de su enseñanza» ${ }^{6}$.

Y esta es una de las razones que ya esgrime Gil de Zárate en su $M a-$ nual para requerir el cambio de sentido en la orientación de estos estudios. Entiende Gil de Zárate que los principios y las reglas que deben guiar a los escolares en la composición de las obras literarias han sido demasiadas veces discutidos y por tanto esta materia se encuentra ya agotada. Motivo por el que defiende la necesidad de dar un nuevo giro a una enseñanza de la literatura basada en el aprendizaje de los preceptos literarios. «Fácil nos hubiera sido -escribe este autor- dar en pocas páginas los nombres y definiciones de las figuras retóricas, de las partes de un discurso, y de las diferentes composiciones en prosa y verso; pero opinamos que poco se consigue cargando la memoria de los principiantes con semejantes cosas, si no se les enseña al propio tiempo a discurrir iniciándoles en los misterios de más altas doctrinas; por esta razón, pasando rápidamente sobre ciertos puntos, nos detenemos algo en los que creemos más importantes, ya porque encierran principios sobre los cuales conviene fijar la atención, ya porque dan a conocer mejor la índole de nuestra literatura. Esta última consideración nos ha hecho añadir la segunda parte que se reduce a un resumen breve, pero crítico y razonado, de nuestra historia literaria: de suerte que con esta obrita tendrán los principiantes lo que no hallarán en ninguna otra, a saber: los principios y reglas generales para la composición; y una guía que les conduzca por el inmenso campo de nuestra literatura, para saberla apreciar suficientemente, y conocer lo que deben huir o estudiar en ella» ${ }^{7}$. Gil de Zárate interpreta bien este momento de transición y asentamiento del liberalismo que ha ganado la guerra civil y propone, a la par que se reorganiza social, política y académicamente el país, compatibilizar la enseñanza de la Retórica con la Historia de la Literatura en los cursos de ampliación de la segunda enseñanza. Del siguiente modo justifica el autor la implantación de la Historia de la Literatura en la enseñanza: «Habiendo dado en la primera parte de esta obra las reglas generales del buen decir, así en verso como en prosa, y las particulares de cada uno de los principales géneros de composiciones literarias que se conocen, réstanos presentar una idea general de la literatura española. Vasto asunto que apenas haremos más que tocar; pero en el cual seguiremos la misma marcha que hemos adoptado anteriormente: sin perjuicio de la brevedad, procuraremos no ser tan lacónicos que la reseña que hagamos sea una mera

${ }^{6}$ Archivo del Instituto «Nicolás Salmerón». Almería. Expedientes de grado de bachiller, A-Z, curso $1849-50$, tomo $3, \mathrm{n}^{\circ} 5$.

7 A. GIL DE ZÁRATE, op. cit., p. 4. 
lista de los autores y sus obras, falta de crítica e insuficiente para dar el necesario conocimiento de nuestras riquezas literarias. Nos proponemos entrar en cuantos pormenores sean compatibles con la naturaleza de este escrito; y no sólo haremos aquellas reflexiones generales que creamos oportunas para delinear con exactitud el carácter que ha tomado entre nosotros cada género de literatura, sino que también nos detendremos en analizar la índole de nuestros principales poetas y prosistas, citando trozos de cada uno, a fin de que se admiren sus bellezas y se eviten sus defectos. De esta suerte uniremos la práctica a la teoría, y a par de las reglas necesarias para escribir con acierto, tendrán los jóvenes una indicación de las fuentes adonde deben acudir para perfeccionar su educación literaria, y de los modelos que pueden seguir con preferencia» ${ }^{8}$.

Las Historias de la literatura, en el momento en que, desplazando a las retóricas, se convierten en el centro de la educación literaria, abren nuevos caminos para la interpretación y análisis de la obra literaria y completan y acaban sustituyendo con esta visión histórica de la literatura los anteriores aprendizajes normativos de las retóricas. Al lado de estos aprendizajes retóricos se va abriendo camino la visión positivista de la literatura: el estudio de los textos, la edición crítica de obras, la investigación sobre las fuentes, el conocimiento de la vida de los autores y la concepción de la obra como expresión del creador y como documento histórico que encarna el espíritu de la época y del pueblo al que pertenece se erigen en el centro y alternativa a la enseñanza basada en preceptos y en buenos modelos clásicos. «El centro de gravedad del trabajo - escribe Kayser- se inclinaba en el siglo XIX, en un principio, hacia la historia de la literatura, mientras que la poética desacreditada y comprometida por las tendencias normativas del siglo XVIII, sólo era favorecida por pensadores aislados. Durante algún tiempo pareció que la ciencia de la literatura y la historia de la literatura eran una sola cosa. Dentro de la historia de la literatura, la noción del poeta, del creador, se reveló como la más fecunda. Basta consultar la mayoría de las historias de la literatura, aún hoy representativas, para comprobar que, en el fondo, no son más que un encadenamiento de monografías sobre poetas» ${ }^{9}$.

El Manual de Gil de Zárate pone de manifiesto en sus comienzos dos de los aspectos sobre los que se vertebrará esta primera Historia de la Literatura para escolares de secundaria: la necesidad de educar literariamente a los jóvenes - conociendo a poetas y prosistas que les valgan como modelos y aprendiendo las reglas y convenciones de lo literario- a la par

${ }^{8}$ A. GIL DE ZÁRATE, Manual de literatura. Segunda parte. Resumen histórico de la literatura española, Tomo I, Madrid, Boix editor, 1844, p. 3-4.

9 W. KAYSER, Interpretación y análisis de la obra literaria, Madrid, Gredos, 1970, p. 28. 
que interiorizan las cualidades o caracteres de dicha literatura que conformaron el espíritu español, la nacionalidad española. «El espíritu cristiano y monárquico, el galanteador y pundonoroso, estaban, pues, fuertemente impresos en el carácter español, y debían reflejarse en la literatura. A esto se añade un tinte oriental muy subido, y por lo tanto, una gran tendencia a lo maravilloso, a las metáforas, a las imágenes atrevidas, a la pompa del lenguaje. Esta última cualidad no fue posible mientras la lengua permaneció ruda y grosera; más luego que se pulió, luego que hubo adquirido flexibilidad y armonía, debió manifestarse, y así sucedió tal vez con reprensible exceso. La literatura que tuviese todas estas cualidades que acabamos de enumerar, era por consiguiente la única que representaba la sociedad española; la única que podía tener eco en todas las clases activas de la misma sociedad...; sólo ella, en fin, era capaz de satisfacer los deseos de todos, y de ser, cual debe toda literatura verdaderamente nacional, original y espontánea» ${ }^{10}$.

Y, como se aprecia en la misma cita, la cuestión del evolucionismo biologicista de la literatura española empieza a estar presente desde que da comienzo el Manual con el Poema del Cid. «Este primer vagido de nuestra poesía, no merece el nombre de poema, no siendo más que una historia o crónica rimada de cierta parte de los hechos de aquél célebre guerrero. Por lo que en él se advierte, el arte métrica estaba tan en su infancia, que aún no se había acertado a inventar un género de verso, que por la armonía y constante cadencia, mereciese el nombre de tal; pues más bien que versos, se encuentran en este poema renglones, cuya medida se percibe apenas...La rudeza del lenguaje hace además cansada la lectura de esta obra, que sólo se debe considerar como curiosidad literaria» ${ }^{11}$. En general, el repaso que realiza Zárate a la literatura española desde sus inicios hasta el siglo XIV, está pensado para describir y mostrar a los escolares de los estudios de ampliación de la enseñanza secundaria lo que él entiende que son los primeros pasos de nuestro idioma y una literatura sencilla que, aunque luego ha sido tan fecunda, todavía está falta de elegancia, de corrección y armonía. Con el paso del tiempo, y una vez que la «verdadera poesía nacional» sustituye a los antiguos modelos, entraríamos en el período de esplendor de nuestras letras. «En aquel siglo (XVI) de eterna gloria para nuestra nación, no solamente sintió toda Europa el poder de nuestras armas, sino que se elevó nuestra literatura al mayor grado de esplendor posible. El poder de las naciones y la gloria literaria se dan a tal punto la mano, que casi siempre adonde aquél existe le acompaña ésta: parece entonces que todas las fuerzas de una nación, así físicas como intelectuales, se desarrollan a la par, y que un impulso común hace que

\footnotetext{
${ }^{10}$ A. GIL DE ZÁRATE, Manual de literatura. Segunda parte, Op. cit. pp. 14-15.

"Ibid., pp. 16-17.
} 
broten por doquiera grandes hombres en todos los ramos. Siglo de oro de nuestra literatura se ha llamado el siglo XVI, y si bien ya a fines de él empezó el buen gusto a estragarse, cuenta gran número de aventajados poetas» ${ }^{12}$. Y Lope de Vega, ya de la mano del positivismo, deja de ser el ejemplo inimitable para los escolares de secundaria, una vez que, apartándose de los antiguos, adivina el drama de la edad moderna y consigue el mayor servicio a nuestra literatura al lograr el maridaje de la literatura popular y la erudita. En cambio, Góngora, vituperado por las Historias de la literatura, y para cuya revalorización habrá que esperar casi medio siglo, es también aquí duramente criticado por llevar «la hinchazón y la extravagancia hasta el delirio», por su pésimo gusto y por el frecuente uso de imágenes atrevidas y metáforas extrañas. Valga como ejemplo un fragmento del comienzo de las Soledades con el comentario que se realiza a los escolares:

\author{
«Era del año la estación florida \\ En que el mentido robador de Europa \\ (Media luna las armas de su frente, \\ $\mathrm{Y}$ el sol todos los rayos de su pelo) \\ Luciente honor del cielo, \\ En campos de zafiro pace estrellas; \\ Cuando el que ministrar podía la copa \\ A Jupiter, mejor que el garzon de Ida, \\ Naufragó, y desdeñado sobre ausente, \\ Lagrimosas de amor dulces querellas \\ $\mathrm{Da}$ al mar, que condolido, \\ Fue a las ondas, que al viento \\ El mísero gemido \\ Segundo de Arión, dulce instrumento».
}

En todo este trozo - se les explica - «no hay más que el primer verso que se entienda, y él bastaba para decir que se estaba en la primavera» ${ }^{13}$.

Algo similar sucede con Quevedo, a quien, a pesar de ensalzar su capacidad, su talento y erudición, debido al uso del lenguaje, a la trabazón del discurso y, sobre todo, atendiendo a razones morales, desaconsejan ponerlo en manos de los jóvenes, porque «Siempre será un modelo peligroso para los principiantes dispuestos siempre a contagiarse con los resabios de mal gusto, y las agudezas extravagantes aunque ingeniosas que a cada paso deslucen sus escritos» ${ }^{14}$.

Hoy conocemos los excesos de este modelo historicista: la sobre valoración del poeta frente a la obra —extremo que hizo exclamar a Kayser: «El

\footnotetext{
${ }^{12}$ Ibid., pp. 100-101.

13 Ibíd., p. 190.

${ }^{14}$ Ibíd., p. 193.
} 
poeta no está incluido en el objeto de la ciencia de la literatura» ${ }^{15}$ - y la reducción de los aprendizajes literarios poco menos que a un listín telefónico de autores y obras similar a la ristra de reglas en que había quedado reducido el modelo retórico.

Además, la investigación centrada en estos manuales de Historia literaria pone de manifiesto el modo en que se han seleccionado los autores que iban a servir como modelos para la enseñanza. Estas Historias de la literatura y las antologías que comparten protagonismo con ellas en los centros educativos son responsables de la selección de los autores que, por razones lingüísticas, literarias, didácticas, morales, ideológicas o políticas, han pasado a formar parte del canon literario moderno. Sin dichas Historias de la literatura nuestros itinerarios pedagógicos hubieran sido muy otros, y la lista de autores en que hemos basado nuestra educación literaria también habría diferido grandemente con el sólo hecho de que hubiera prevalecido la educación retórica anterior a 1845 .

Asimismo, de haber alguna cuestión central y común a dichas Historias de la literatura, ésta no es otra, como hemos adelantado, que la de la nacionalidad, la de la formación del carácter nacional.

Concepto de nacionalidad que elaboran y/o trasladan a las Historias de la literatura los pioneros: Gil de Zárate, Amador y, sobre todo, Menéndez Pelayo. Éste sustenta dicho concepto, por un lado, en el lugar y la extensión geográfica que tales Historias abarcan; y por otro, en la lengua y el estilo literario como «prendas de nacionalidad», como elementos que conforman lo nacional. El mencionado concepto también tendrá otras y muy diversas ramificaciones a lo largo del siglo XIX hasta llegar a la formulación nacional-católica que hicieran los franquistas durante la posguerra. Recuérdese, y así concluimos, que las autoridades educativas franquistas reclaman que este sentido nacional patriótico y religioso impregne todas las enseñanzas y sirva de sostén a la nueva España «esencialmente católica». Concretamente, el director de Enseñanza Media, José Pemartín, proclama que la esencia de España como nación es su ferviente catolicismo, catolicismo que ha de encarnarse en un cuerpo social fuerte que, en esos momentos de guerra civil, enuncia valiéndose de Maeztu: ser es defenderse. Si España quiere ser -escribe Pemartín ${ }^{16}$-, este ser de España ha de expresarse en pocas palabras: cañones, acorazados, submarinos y aviones.

${ }^{15}$ W. KAYSER, op. cit., p. 20.

16 J. Pemartín, Qué es «lo nuevo»... Consideraciones sobre el momento español presente, Madrid, Espasa Calpe, 1940, p. 323. 


\title{
RESUMEN
}

Las historias de la literatura y la enseñanza pública, por Gabriel Núñez Ruiz.

El objeto de este trabajo no es otro que el de enjuiciar el papel que jugaron las Historias de la literatura en la educación de los escolares españoles, especialmente desde el momento en que se promulga el primer plan de estudios moderno y con él ve la luz la primera Historia de la Literatura de la España contemporánea: la de Gil de Zárate.

Palabras clave: Educación literaria. Historias de la literatura.

\begin{abstract}
The aim of this study is to assess the role of Histories of Literature in the education of Spanish pupils, especially from the moment when the first modern school curriculum is established and with it appears the first History of Literature in contemporary Spain: that of Gil de Zárate.
\end{abstract}

Key words: Literary education, Histories of Literature 